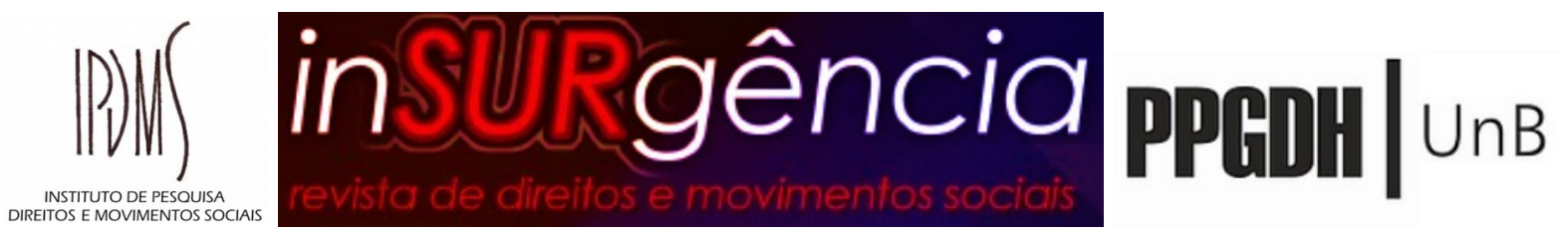

\title{
APRESENTAÇÃO
}

A nova edição da revista InSURgência, volume 6, número 2, relativa ao período de julho a dezembro de 2020, tem o intuito de aprofundar as discussões sobre Cidade e Direito, o que motivou o Dossiê "Política fundiária na produção e gestão das cidades na América Latina”, organizado por André Felipe Soares Arruda, Anna Carolina Lucca Sandri, Henrique Botelho Frota, João Aparecido Bazzoli e Marcelo Eibs Cafrune, integrantes do Grupo de Trabalho “Cidade e Direito” do Instituto de Pesquisa, Direitos e Movimentos Sociais IPDMS.

A temática do acesso à terra é fundamental para explicar a realidade brasileira, marcada por uma estrutura fundiária em que a vinculação do acesso à terra com a propriedade exclui parcela significativa da população, que é condenada à insegurança jurídica da posse e tem seu acesso a políticas públicas prejudicado.

Recentemente, com o golpe de 2016 ocorreram mudanças na política de regularização fundiária urbana, mediante a Medida Provisória n 759/2016, posteriormente convertida na Lei ${ }^{0}$ 13.465/2017, motivadas por interesses do mercado, o que se refletiu na ampliação das possibilidades de regularização fundiária direcionada para imóveis de alto padrão, o que em áreas públicas visou a regularização da grilagem.

Esse novo marco legislativo suscitou inúmeras discussões sobre sua inconstitucionalidade e também sobre as novas possibilidades de regularização fundiária de interesse social, em razão da simplificação e flexibilização desse processo, o que torna ainda mais necessário a avaliação dessa lei sob a perspectiva da regularização fundiária urbana.

No governo Bolsonaro houve a intensificação da criminalização dos movimentos sociais e a intenção de restringir ainda mais a aplicação da função social da propriedade, expressa na Proposta de Emenda à Constituição - PEC nº 80/2019. As periferias também estão condenadas à contaminação e à falta de alternativas de renda pela ausência de uma política efetiva de controle à pandemia do Covid-19. Nesse contexto de inúmeros retrocessos torna-se ainda mais fundamental a difusão da pesquisa crítica que contribua com os movimentos populares. 


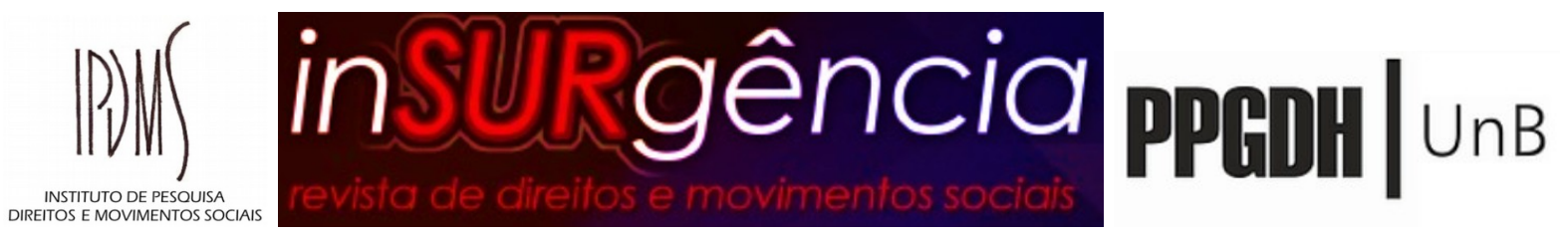

Nessa direção, a seção de Diálogos Insurgentes conta com as entrevistas da liderança do Movimento dos Trabalhadores Sem Teto - MTST, Guilherme Boulos, e de Betânia Alfonsin, cuja trajetória foi importante para a conformação do direito urbanístico no Brasil. Ambas as entrevistas se conectam na abordagem do histórico da política fundiária brasileira, que culminou na exclusão da maioria do povo do acesso à terra, e problematizam os impactos do golpe de 2016 para a regularização fundiária e políticas habitacionais.

Essa temática perpassou o dossiê da revista, inclusive com alguns artigos que se debruçaram sobre os impactos surgidos com a Lei $n^{0}$ 13.465/2017. Nessa toada, o artigo "Direito e espoliação: como a legitimação fundiária demonstra os limites e possibilidades de um Direito insurgente” de Carolina Hennig Gomes e José Luiz Amorim Ribas Filho apontou o alinhamento da legitimação fundiária instituída por esse novo marco legal com os processos de acumulação de capital, ao passo que a luta dos movimentos sociais pela reivindicação de Regularização Fundiária Urbana - REURB se aproximaria de um direito insurgente contraposto aos processos de acumulação por espoliação.

O artigo "Moldando o direito à norma: o Conto de Pontal e o Porto e apropriação privada de terras comuns”, de Isabella Madruga da Cunha, analisa o processo de apropriação privada de terras devolutas no litoral do Paraná, iniciado na década de 1950. Inclusive em parte desse território destinado para empresas estão sendo instalados empreendimentos portuários, que trazem impactos para comunidades tradicionais da região.

A concepção presente no novo marco legal reflete as teorizações do economista peruano Hernando de Soto, que defende uma proposta de regularização fundiária que consiste na mera formalização das propriedades imobiliárias, que iria proporcionar a superação da pobreza e a garantia do sucesso do capitalismo nos países subdesenvolvidos. É nesse debate que se insere o artigo "É possível equacionar o problema da pobreza via economia de mercado? A política de formalização da propriedade imobiliária em Hernando de Soto”, de Alex Ferreira Magalhães, que realiza uma análise crítica da teoria do economista peruano, questionando que a formalização visa mais a constituição de empreendedores do que de cidadãos.

Ainda que o novo marco legal traga esse foco na titulação individual, o artigo "Novos olhares sobre a Lei 13.465/17: Potencialidades no Fortalecimento das Comunidades através 


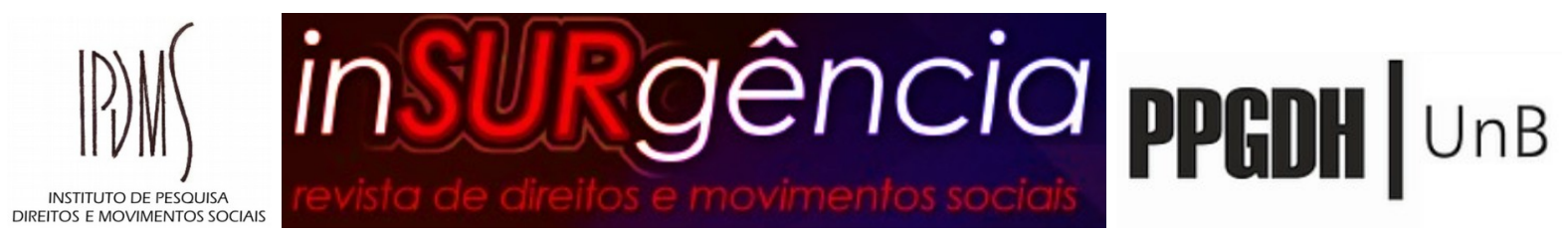

dos Termos Territoriais Coletivos” de Tarcyla Fidalgo Ribeiro explora as possibilidades da nova lei de regularização em facilitar a implementação do modelo dos Termos Territoriais Coletivos, modelo de gestão coletiva da terra, em comunidades urbanas.

As possibilidades e limites da aplicação da Lei $n^{0}$ 13.465/2017 para realização de regularização fundiária de interesse social também foi tratado no artigo "Ocupações urbanas em Minas Gerais: uma análise da política fundiária a partir da luta pelo direito à cidade” de Luiz Fernando Vasconcelos de Freitas e Thayan Rodrigues Coutinho Neves, a partir de casos concretos envolvendo ocupações urbanas em Minas Gerais.

A violação do direito à moradia, em decorrência do descumprimento da função social da propriedade urbana, também está presente na experiência da Missão em Defesa do Direito à Moradia Digna nas Ocupações Urbanas, em São Leopoldo (RS), discutida no artigo "Função social da propriedade urbana e a luta pelo direito à cidade: uma análise a partir da experiência da missão em defesa do direito humano à moradia digna nas ocupações urbanas da cidade de São Leopoldo (RS) ”, de Karina Macedo Fernandes.

O artigo "Contradições do sistema normativo urbano-ambiental e as práticas insurgentes de produção do lugar em São José do Norte, RS”, de Rita de Cássia Gnutzmann Veiga e Marcelo Eibs Cafrune, mediante a análise de inquéritos civis do município de pequeno porte, São José do Norte (RS), abordou os entraves para garantia do direito à moradia advindos de limitações da ocupação do solo pela legislação ambiental, o que denota a seletividade da tutela ambiental empregada para remoções da população de baixa renda.

O controle das políticas públicas sobre o direito à moradia pelo Poder Judiciário foi abordado com o artigo “Atuação judicial e controle de políticas públicas: o exemplo da Apelação Cível $\mathrm{n}^{\circ}$ 1.0194.10.011283-3/001 na tutela do direito fundamental à moradia por meio do reconhecimento da usucapião sobre bem público”, de Scheila Santos Rolemberg, que esmiuçou o reconhecimento do usucapião sobre bem público.

A intervenção estatal para garantia do direito à moradia em regiões dotadas de infraestrutura urbana perpassou o artigo “A sabotagem das Zonas Especiais de Interesse Social de vazio pelo Município de Fortaleza: um indicativo do abandono das ZEIS como instrumento de política urbana e de regularização fundiária na cidade?”, de Cynara Monteiro 


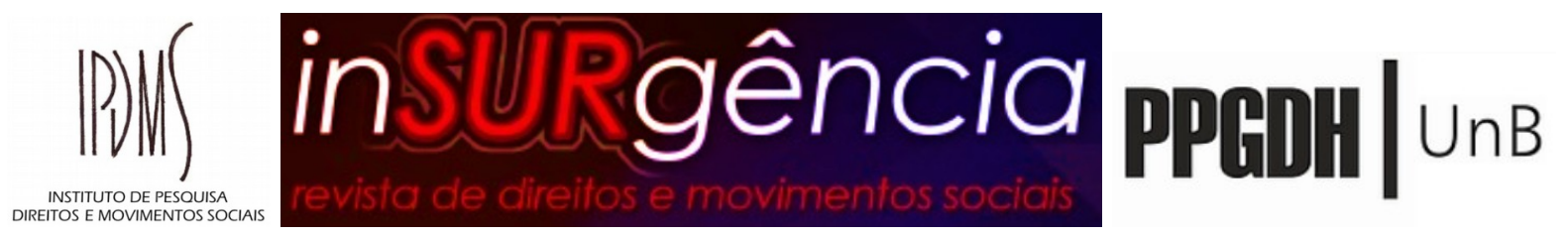

Mariano, Harley Sousa de Carvalho e Guilherme Bezerra Barbosa, em que se evidenciou a inviabilização pelo município de Fortaleza da utilização das Zonas Especiais de Interesse Social - ZEIS em áreas de vazios urbanos.

Já na seção de artigos livres, a contribuição “A descolonização dos patrimônios subalternizados e o reconhecimento da insurgência patrimonial dos quilombos no Brasil” de Paulo Fernando Soares Pereira, apontou para as possibilidades de descolonização patrimonial, a partir do tombamento da patrimonialidade quilombola, caso seja assegurada voz aos sujeitos subalternizados no processo colonial, já que a conquista de direitos é resultado de lutas políticas empreendidas por esses sujeitos.

Na seção de temas geradores, composta por verbetes, apresentamos as "Notas sobre o direito à cidade”, de Alvaro Luis dos Santos Pereira e Giovanna Bonilha Milano, em que se apresentam perspectivas de formulações distintas sobre o direito à cidade e os debates relativos ao papel do Estado no cumprimento do direito à cidade. O verbete "Conflitos fundiários urbanos”, de Anna Carolina Lucca Sandri e Marcelo Eibs Cafrune, buscou apresentar uma definição desses conflitos, sujeitos que o integram, constatações surgidas pelo modo como o Poder Judiciário gere esses conflitos e possibilidades de mediação.

A seção de "Poéticas políticas" é constituída pela fotografia "quem não pode com a formiga não atiça o formigueiro” de Henrique Botelho Frota, pelas poesias “'Pra virar gente': uma antropoesia” de Lênora Santos Peixoto, "Progresso" de Assis da Costa Oliveira, "O que nos esvazia” de Rodrigo de Medeiros Silva e pelo compilado de textos "Pisantes poéticas: palavras do concreto” de Helga Maria Martins de Paula, Angélica Ferreira de Freitas, Brunna Teodoro Queiroz e Renata de Mello Mamede.

Já na seção “Caderno de retorno”, a resenha “As propriedades da propriedade: aportes para estudar o espaço urbano em 'The properties of property”, de Guilherme Stefan, Mateus Cavalcante de França e Raissa Rayanne Gentil de Medeiros, apresentou uma análise do artigo “The properties of property” dos antropólogos do direito Franz von Benda-Beckmann, Keebet von Benda-Beckmann e Melanie G. Weber, em que a propriedade é concebida como perpassada por inúmeras práticas sociais, por isso, os autores defendem a organização social nas seguintes camadas: jurídico-institucional, relações sociais concretizadas e ideológica. 


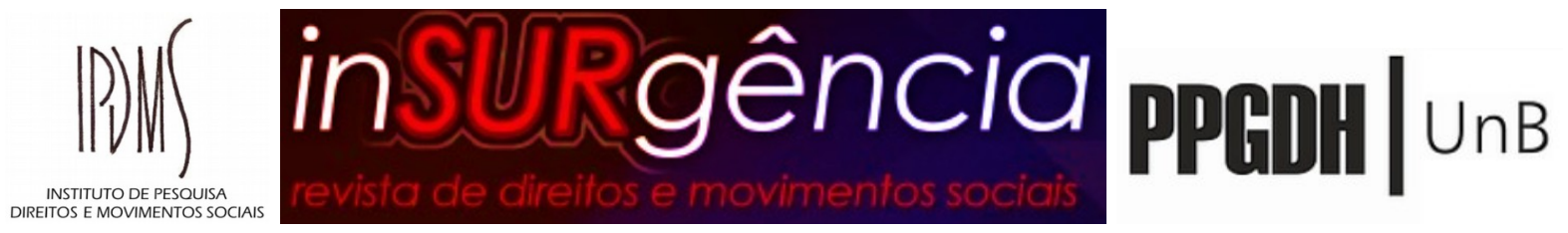

A resenha do artigo "Cidade - Espaço público? A economia política do consumo nas e cidades” de Henri Acselrad, realizada por Marcelo Eibs Cafrune, Bruna Ramires Vieira, Emanuele Gebeluky Pinheiro, Marcela de Avellar Mascarello, Tâmara Circe Cerpa Moraes e Yago Freitas Blanco, aborda o processo de apropriação privada dos espaços públicos urbanos, em decorrência da emergência do planejamento estratégico e empreendedorismo urbano, pois a lógica mercantil se incorporou nos espaços urbanos, de modo a priorizar o consumismo, o que acarreta na sua própria descaracterização desses locais como espaços públicos.

Esperamos que a presente edição contribua para o aprofundamentos dos debates sobre o direito à cidade, sobre as lutas populares pela moradia e sobre a necessária crítica aos atuais instrumentos jurídicos e à atuação do Estado para a garantia dos direitos das comunidades que vivem nas periferias das cidades.

\section{Comitê editorial:}

Alexandre Bernardino Costa

Diego Augusto Diehl

Diogo Pinheiro Justino de Souza

Guilherme Cavicchioli Uchimura

Moisés Alves Soares

Talita de Fátima Pereira Furtado Montezuma

Urânia Flores da Cruz Freitas

\section{Comissão de Organização:}

André Felipe Soares Arruda

Anna Carolina Lucca Sandri

Henrique Botelho Frota

João Aparecido Bazolli

Marcelo Eibs Cafrune 